\title{
IMPLEMENTASI LEAN DENGAN MENGGUNAKAN METODE IMPROVEMENT KATA \& COACHING KATA PADA PERUSAHAAN PENYEDIA LAYANAN LOGISTIK
}

\author{
${ }^{1}$ Tri Widodo, ${ }^{2}$ Ismail Fardiansyah \\ 1,2. Program Studi Teknik Industri, Fakultas Teknik \\ Universitas Muhammadiyah Tangerang \\ Jl. Perintis Kemerdekaan I/33, Cikokol, Kota Tangerang \\ Email : ${ }^{1}$ tiga_wd@yahoo.co.id, ${ }^{2}$ fardiansyahismail@yahoo.com
}

\begin{abstract}
A b s trak
Perusahaan yang bergerak di bidang penyedia pelayanan logistik memiliki Divisi Contract Logistic, yang mengurusi kontrak warehousing dengan para pelanggannya. Operasional yang ada di warehouse meliputi inbound, storage, dan outbound. Agar dapat bersaing dan memenuhi keinginan pelanggannya, salah satu upaya yang dilakukan adalah mengadopsi konsep lean dengan mengimplementasikan metode Improvement Kata dan Coaching Kata. Metode Kata ini digunakan karena sangat berfokus pada pelaksanaan improvement dengan memberdayakan atau melibatkan karyawan. Penelitian ini membahas mengenai salah satu case study yang diselesaikan menggunakan metode KATA pada proses inbound. Proses inbound yang akan akan dibahas yaitu aktivitas put away untuk produk single sku. Implementasi improvement kata dan coaching kata pada aktivitas put away produk single sku berhasil mereduksi waktu proses put away dari 360 detik per pallet menjadi 105 detik per pallet, selain itu hasil yang dicapai yaitu dapat meningkatkan produktivitas dari 5 pallet/manhour menjadi 34 pallet/manhour.
\end{abstract}

Kata Kunci : Improvement kata, Coaching kata, Put away, Produktivitas.

\section{PENDAHULUAN}

Ehni dan kersten (2015) mengungkapkan bahwa Kondisi bisnis saat ini sangatlah kompetitif, hal ini terlihat dengan suasana kejenuhan pasar atau meningkatnya permintaan pasar, agar dapat bertahan dalam kondisi seperti ini merupakan tuntutan bagi pelaku bisnis, salah satu yang di lakukan adalah dengan mengimplemetasikan lean management atau continuous improvement.

Belajar dari Toyota yang melakukan pendekatan berbeda, dengan jalan mempercayakan karyawan yang ada di floor untuk melakukan improvement dengan tujuan berkesinambungan dan berorientasi pada hasil. Kata merupakan metode atau jalan yang dapat digunakan untuk mengembangkan lean management. Rother (2015) menyatakan bahwa kata adalah rutinitas latihan yang membantu kita mengadopsi cara bertindak dan berpikir baru.

Menurut Reverol (2012) : menerima perubahan bukanlah hal yang mudah tentu akan menimbulkan resistensi, karyawan terbiasa melakukan hal-hal dengan cara mereka. Kata merupakan metode yang tepat, karena kata adalah metode pemberdayaan karyawan untuk menciptakan improvement berdasarkan pengetahuan dan pembelajaran berkelanjutan dari proses tersebut.

Berangkat dari fenomena-fenomena diatas, maka Penelitian ini akan membahas salah satu kaizen busrt dari workshop VSM yang pernah dilakukan sebelumnya yang di pecahkan dengan menggunakan metode kata improvement. Operasional yang ada di warehouse meliputi inbound, storage, dan outbound.

Improvement kata memiliki banyak keuntungan dalam percepatan kondisi ideal, dikarenakan kata menggunakan metode yang sangat cepat, yang merupakan integrasi langkah PDCA dengan penerapan aktivitas yang lebih kecil atau detail, mudah untuk memonitor, leader 
memiliki pandangan kedepan yang lebih jelas dalam proses improvement, memberdayakan kelebihan yang dimiliki karyawan dengan lebih cepat (Iberli,K, 2015).

\section{METODE PENELITIAN}

\section{Pengumpulan data}

tahap ini mulailah dilakukan langkah-langkah pengumpulan data yang dibutuhkan untuk mencapai tujuan penelitian. Jenis data yang di ambil pun terbagi menjadi dua, yaitu data primer dan data sekunder

\section{a. Pengumpulan Data Primer}

Data primer yang diambil antara lain adalah gemba yaitu dengan melihat kondisi aktual dan terlibat langsung pada aktitivitas improvement kata dan coaching kata dengan mengambil salah satu contoh case study pada aktivitas put away di proses inbound

b. Pengumpulan Data sekunder

Data sekunder dilakukan dengan mengumpulkan referensi-referensi melaui jurnal ilmiah dan artikel yang terkait dengan improvement kata dan coaching kata. Data sekunder juga di dapat dari daftar rencana improvement yang didapat dari VSM (Value Stream Mapping)

\section{Penentuan Tantangan atau Challenge}

Penentuan Tantangan adalah dengan mengambil salah satu kaizen burst dari VSM yang sudah dijalankan sebelumnya.

\section{Analisa Kondisi Saat ini atau Current Condition}

Melakukan pengukuran pada kondisi saat ini atau pada masalah yang sedang diselesaikan, yaitu aktivitas putaway pada proses inbound untuk produk single sku.

\section{Menetapkan Target Kondisi atau Target Condition}

Penetuan target kondisi yang diharapkan untuk mencapai challenge yang ada. Penetuan kondisi ini juga bersamaan dengan penentuan target waktu untuk mencapainya.

\section{Melakukan Eksperimen}

Untuk merealisasikan target kondisi dari kondisi saat ini, maka didapat beberapa rintangan atau obstacle. Maka setiap obstacle ini dilakukan pemecahan masalah melalui eksperimen-eksperimen.

\section{HASIL DAN PEMBAHASAN}

Salah satu kaizen burst atau problem dari workshop VSM yang dilakukan adalah proses put away produk single SKU full pallet. Maka dari itu kaizen busrt ini yang diangkat untuk diselesaikan menggunakan metode kata. Seorang pembelajar melakukan proses coaching dengan seorang pelatih dengan urutan atau langkah penyelesaian masalah sebagai berikut:

1. Penentuan tantangan atau challenge

Fokus proses ada di aktivitas put away pada proses inbound, dengan challenge yaitu put away single sku menggunakan 1 operator MHE, dengan Proses waktu $180 \mathrm{sec} /$ pallet atau produktivitas 20 Pallet/manhours

\section{Analisa Kondisi Saat ini}

Kondisi saat ini diketahui :

- Proses put away single $S K U$ membutuhkan 2 man power

- Put away membutuhkan waktu selama 360 detik/pallet, dengan productivity 5 pallet/ manhours

- Lokasi yang tersedia untuk putaway hanya diketahui oleh admin 
- over processing : penempelan label nomor pallet dan scan dilakukan saat berada dilokasi put away

3. Menetapkan Target Kondisi

Untuk mencapai tantangan atau challenge maka ditentukan target kondisi melalui proses coaching, antara lain :

- $\quad$ put away proses single SKU menggunakan 1 MHE Operator

- Operator MHE mengetahui lokasi yang tersedia

- Label IN sudah menempel pada product sebelum Putaway

Dari target kondisi yang ditentukan maka terdapat beberapa rintangan atau obstacle, antara lain :

- $\quad$ Operator MHE belum mempunyai skill untuk proses Scan menggunakan RF

- $\quad$ Lokasi sugestion put away belum tersedia

- $\quad$ proses penempelan IN saat berada di lokasi put away

Maka semua hasil coaching kata tersebut dimasukkan kedalam Kata Story Board, seperti dibawah ini:

Tabel 1. Kata Story Board Aktivitas Putaway Single Sku

\begin{tabular}{|c|c|c|c|}
\hline \multicolumn{2}{|l|}{ Focus Process } & \multicolumn{2}{|l|}{ Challenge } \\
\hline \multicolumn{2}{|c|}{$\begin{array}{l}\text { Proses putaway single SKU full pallet } \\
\text { By MHE Operator }\end{array}$} & \multicolumn{2}{|c|}{$\begin{array}{l}\text { Proses single SKU menggunakan } 1 \text { MHE OP, dengan } \\
\text { Proses waktu } 180 \mathrm{sec} / \text { pallet atau } 20 \text { Pallet/manhours }\end{array}$} \\
\hline Target Condition & Current Con & dition & Obstacles Parking Lot \\
\hline $\begin{array}{l}1 \text { put away proses single } \\
\text { SKU menggunakan } 1 \mathrm{MHE}\end{array}$ & $\begin{array}{l}\text { 1. Menguna } \\
\text { 2 (a) Process } \\
\text { (b) produc }\end{array}$ & $\begin{array}{l}\text { kan } 2 \text { Operator } \\
\text { ing Time : } \\
360 \mathrm{Sec} / \text { pallet } \\
\text { ivity : } \\
5 \text { pallet / }\end{array}$ & $\begin{array}{l}\text { 1. Operator MHE belum } \\
\text { mempunyai skill untuk proses } \\
\text { Scan menggunakan RF }\end{array}$ \\
\hline $\begin{array}{l}\text { 2. Operator MHE } \\
\text { mengetahui lokasi yang }\end{array}$ & $\begin{array}{l}\text { 3. Sugestion } \\
\text { by admin un } \\
\text { masih terse }\end{array}$ & $\begin{array}{l}\text { alternatif lokasi } \\
\text { tuk lokasi yang } \\
\text { dia }\end{array}$ & $\begin{array}{l}\text { 2. lokasi yang full sehingga untuk } \\
\text { sugestion putaway belum tersedia }\end{array}$ \\
\hline $\begin{array}{l}\text { 3. Mengurangi waktu } \\
\text { Putaway single SKU } 10 \% \text {, } \\
\text { dengan label IN sudah } \\
\text { menempel pada product } \\
\text { sebelum Putaway }\end{array}$ & $\begin{array}{l}\text { 4. Operator } \\
\text { untuk mene } \\
\text { lalu melaku } \\
\text { rack, lalu tur } \\
\text { melakkukan }\end{array}$ & $\begin{array}{l}\text { MHE harus turun } \\
\text { mpel label IN, } \\
\text { kan put away di } \\
\text { un kembali untuk } \\
\text { scan }\end{array}$ & $\begin{array}{l}\text { 3. proses penempelan IN saat } \\
\text { berada di lokasi putaway }\end{array}$ \\
\hline
\end{tabular}

Dari tabel diatas dapat dilihat bahwa terdapat 3 obstacle untuk mencapai tantangan. Selanjutnya masing-masing obstacle dilakukan eksperimen menggunakan PDCA Eksperimen logbook.

\section{Eksperimen}

Eksperimen dilakukan berurutan berdasarkan urutan obstacle yang didapat. Berikut ini adalah contoh Eksperimen untuk obstacle pertama :

\section{PDCA Experiment Logbook 1}

Obstacle pertama yaitu operator MHE belum mempunyai skill untuk proses scan menggunakan RF. Hasil dari proses coaching di sepakati bahwa eksperimen yang akan dilakukan adalah pelatihan scan RF GUN untuk operator $M H E$. Ekspektasi dari eksperimen ini adalah operator MHE bisa melakukan scan saat proses putaway menggunakan RF GUN. Berikut PDCA Ekperimen logbook 1: 
Tabel 2. PDCA Experiment Logbook Aktivitas Put away Single Sku

\begin{tabular}{|c|c|c|c|c|c|}
\hline \multirow{3}{*}{\begin{tabular}{|l} 
Obstacle \\
Experiment, \\
Date
\end{tabular}} & \multirow{2}{*}{\multicolumn{2}{|c|}{$\begin{array}{l}\text { Operator MHE belum } \\
\text { mempunyai skill untuk proses } \\
\text { putaway menggunakan RF }\end{array}$}} & Focus Process & \multirow{2}{*}{\multicolumn{2}{|c|}{$\begin{array}{l}\text { Proses putaway single SKU full pallet By } \\
\text { FIPIT FITROKHIM }\end{array}$}} \\
\hline & & & \multirow{2}{*}{\multicolumn{2}{|c|}{ Apa hasil dari }} & \\
\hline & $\begin{array}{l}\text { Apa yang Anda harapkan } \\
\text { dari percobaan ini? }\end{array}$ & & & & $\begin{array}{l}\text { Apa yang Anda pelajari } \\
\text { dari eksperimen? }\end{array}$ \\
\hline $\begin{array}{l}\text { Training RF } \\
\text { GUN untuk } \\
\text { OP MHE ex } \\
\text { Merck } \\
10 \text { OKTOBER } \\
2017\end{array}$ & $\begin{array}{l}\text { Operator MHE bisa } \\
\text { melakukan scan saat } \\
\text { proses putaway } \\
\text { menggunakan RF GUN }\end{array}$ & \multirow[t]{4}{*}{ 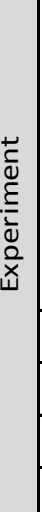 } & \multicolumn{2}{|c|}{$\begin{array}{l}\text { 1. Operator MHE sudah bisa } \\
\text { melakukan proses putaway ITS } \\
\text { menggunakan RF gun }\end{array}$} & $\begin{array}{l}\text { proses putaway single SKU } \\
\text { full pallet By MHE } \\
\text { operator waktu berkurang } \\
\text { menjadi } 340 \mathrm{sec} / \text { pallet } \\
\text { dengan menggunakan } 1 \\
\text { operator }\end{array}$ \\
\hline & & & & & \\
\hline & & & & & \\
\hline & & & & & \\
\hline
\end{tabular}

Hasil eksperimen 1 didapat bahwa Operator $M H E$ sudah bisa melakukan proses putaway dan scan menggunakan RF gun.

Lalu begitu seterusnya eksperimen dilakukan berdasarkan obstacle yang muncul saat coaching kata. Setelah seluruh eksperimen selesai dilakukan, seluruh target condition dapat tercapai dan akhirnya challenge yang ditentukan pun juga terpenuhi. Berikut adalah hasil improvement kata, saat sebelum dan sesudah improvement :

Tabel 3. Perbandingan kondisi sebelum dan Sesudah Improvement

\begin{tabular}{|c|c|}
\hline Kondisi sebelum improvement & Kondisi setelah improvement \\
\hline $\begin{array}{l}\text { - Aktivitas put away single } \\
\text { SKU membutuhkan } 2 \text { man } \\
\text { power } \\
\text { - put away membutuhkan } \\
\text { waktu } 360 \text { detik/pallet } \\
\text { - Produktivitas : } \\
\text { pallet/manhour } \\
\text { - Lokasi put away hanya } \\
\text { diketahui oleh admin } \\
\text { - Penempelan label dilakukan } \\
\text { saat berada dilokasi }\end{array}$ & $\begin{array}{l}\text { - Aktivitas put away dilakukan } \\
\text { oleh } 1 \text { man power: } 1 \text { operator } \\
\text { MHE } \\
\text { - Aktivitas put away } \\
\text { membutuhkan waktu } 105 \\
\text { detik/pallet } \\
\text { - Produktivitas : } 34 \\
\text { pallet/manhour } \\
\text { - Operator MHE mengetahui } \\
\text { suggestion lokasi } \\
\text { - Penempelan label dilakukan } \\
\text { saat akan menuju lokasi }\end{array}$ \\
\hline
\end{tabular}

\section{KESIMPULAN}

Kesimpulan yang dapat diambil dari penelitian ini antara lain :

1. Dengan mengimplementasikan improvement kata dan coaching kata pada proses put away single sku, dapat mempercepat proses putaway dari 360 detik/pallet menjadi 105 detik/pallet.

2. Terjadi peningkatan produktivitas dari 5 pallet/manhour menjadi 34 pallet/manhour.

3. Terjadi komunikasi yang aktif antara atasan sebagai pelatih dan bawahan sebagai pembelajar dalam pemecahan masalah. 


\section{SARAN}

Adapun saran yang bisa diberikan untuk perusahaan antara lain :

1. Terus lakukan improvement untuk challenge lainnya sebagai upaya mencapai tujuan atau visi perusahaan

2. Regenerasi Pelatih dan pembelajar. Pembelajar yang telah menyelesaikan challenge layak untuk menjadi pelatih bagi pembelajar baru.

\section{DAFTAR PUSTAKA}

Benson, J,. Barry, T, D., (2015) Practical Management : Lean and Beyond, Cutter IT Journal, vol.28, No.6.

Ehni, M., \& Kersten, W,. (2015). Toyota Kata : Empowering Employees for Target Oriented Improvement - A Best Practice Approach. Proceedings of the Hamburg International Conference of Logistics (HICL)-20

Hamdulay, F,. (2016). The Evolution of Lean Thinking at Textek- Where to next Teaching Case Study. Thesis. Graduate School of Business, University of Cape Town, South Africa

Iberle, K. (2015) The Improvement Kata: Annual Improvement Planning Meets Agile. PNSQC 2015 Proceeeding. Iberle Consulting Group, Inc. USA

Kalsaas, B, T. \& Briseid, M. (2015). To Increase Employee Engagement in Lean Continuous Improvement. Thesis. Faculty of Engineering \& Science, University of Agder, Norwegia

Reverol, J. (2012). Creating an Adaptable Workforce : Using the Coaching Kata for Enhanced Environmental Performance. Environmental Quality Management, DOI : $10.1002 /$ tqem. 21234

Rother, M. (2015). The challenge of developing lean management (power point slide). Creative Commons Attribution License

Rother, M. (2018). The Toyota Kata Practice Guide. New York : MC Graw Hill Education.

Sarjono, H. (2001). Model Pengukuran Produktivitas Berdasarkan Pendekatan Rasio Output Per Input. Journal The Winners, Vol.2, No.2, September 2001 : 130-136

Toma, Naruo, S, G, \& Shinji (2017). Total Quality Management and Business Excellence : The Best Practice at Toyota Motor Corporation, Amfiteatru Economic Journal, ISSN 22479104, Vol. 19, Iss. 45, pp. 565-585

Uriarte, A,G. Moris, M, U. Amos, H,C,Ng. \& Oscarsson , J. (2015). Lean, Simulation and Optimization: A Win Win Combination. Proceedings of the 2015 Winter Simulation Conference. School of Engineering Science University of Skovde, Sweden . 
